\title{
TEORIA LANEANA: A UNIVOCIDADE RADICAL ALIADA À DIALÉTICA-MATERIALISTA NA CRIAÇÃO DA PSICOLOGIA SOCIAL HISTÓRICO-HUMANA
}

\author{
Bader Burihan Sawaia \\ Pontifícia Universidade Católica de São Paulo, São Paulo, Brasil
}

\begin{abstract}
RESUMO: O texto apresenta o corpo teórico-metodológico que Sílvia Lane criou, ressaltando os seus pressupostos epistemológicos e ontológicos e demarcando os grandes momentos do seu processo de configuração. Um processo dialético que avança incorporando novos conhecimentos sem abandonar o anterior, mas unindo-os na produção de algo novo. Essa metodologia "prático-crítica-revolucionária, inicialmente intuitiva, foi se burilando cientificamente a partir de pesquisas empíricas, segundo Lane, fundamentais para a crítica dos conceitos e avanço da teoria. A tarefa do texto é fácil porque Sílvia registrou cada mudança em seus principais interesses, categorias analíticas e reflexões filosóficas, em seus livros. São quatro os momentos a serem destacados, todos eles de aprofundamento da sua radical superação teórica: a transição de um referencial configurado na interface entre Lewin, Mead, Skinner ao marxismo: (a) dos anos 70, marcado pelo diálogo privilegiado com a teoria das representações e pela preocupação com a linguagem e grupos sociais; (b) dos anos 80 , momento das vigorosas reflexões sobre uma nova concepção de homem para a psicologia, com ênfase nas categorias de consciência e alienação, orientada pela escola de psicologia soviética e por neo-marxistas (Politzer e Heller); (c) dos anos 90, caracterizado pela reflexão sobre o papel da subjetividade/afetividade na conscientização social e na ação transformadora, superando o aprisionamento do sujeito à exterioridade e à pura repetição e o expurgo da singularidade, e pela reafirmação da pesquisa participante e da práxis comunitária; (d) a do novo milênio, dedicado a desvelar os segredos da criatividade humana. Emoção, arte e criação são os temas que passaram a mediar a sua incessante reflexão crítica das teorias e das consequiências práticas da psicologia para a condição social da América Latina. Espera-se, assim, apresentar a processualidade de sua concepção-compromisso de ciência em busca do conhecimento da existência humana sem suturas.
\end{abstract}

PALAVRAS-CHAVE: Praxis psicossocial; psicologia social Latina Americana; singularidade e transformação social; resolução ético-estética.

\section{LANEAN THEORY: THE RADICAL UNAMBIGUOUSNESS ALLIED WITH THE DIALECTIC- MATERIALIST IN CREATING HISTORICAL-HUMAN SOCIAL PSYCHOLOGY}

ABSTRACT: The paper presents the base of Sílvia Lane's theoretical-methodological work, highlighting its ontological and epistemological presumptions and delineating the grand moments of its configuration process. The dialectic process that advances incorporating new knowledge without abandoning the previous, but uniting it in producing something new. This "pragmatic-critical-revolutionary" methodology, initially intuitive, became scientifically chiseled out from empirical research, according to Lane, fundamental for criticizing the concepts and advancing the theory. The task of the text is easy because Sílvia registered in her books each change of her principal interests, analytical categories and philosophical reflections. There are four moments to be highlighted. All of them make a profound study of her radical theoretical overcome: the transition of a configured reference in the interface between Lewin, Mead, Skinner to Marxism: 1) from the 70's, marked by the privileged dialogue with representations theory and with concerns with language and social groups; 2) from the 80's, a time of vigorous reflections on a new conception of man for psychology, with emphasis on the categories of consciences and alienation, orientated by soviet psychology and neo-marxism (Politzer and Heller); 3) from the 90's, characterized by the reflection on the role of subjectivity/affectivity on social awareness and on transformative action, overcoming the subject's imprisonment to exteriority and to pure repetition and the purge of singularity, and by reaffirming participant research and community praxis; 4) from the new millennium, dedicated to unveil the secrets of human creativity. Emotion, art and creativity were the themes that became to mediate her incessant critical thoughts on psychology's theories and practical consequences for Latin America's social con-dition. Thus, this paper hopes to present the process of her conception-compromise of science in search of the knowledge of boundless human existence.

KEYWORDS: psychossocial praxis; Latin American Social Psychology; singularity and social transformation; ethicalesthetic resolution. 
A teoria laneana é vibrante e inspiradora, porque ela é a transfiguração em palavras de sua essência como sujeito da história, amoroso, angustiado, tenaz, intransigentemente ético, estético nas mínimas ações cotidianas e com muitos e diversos interesses.

Sílvia viveu, plenamente, a concepção de homem/ mulher que sua teoria de fende, um indivíduo por inteiro, sem suturas, tolhido (em sua particularidade social) pelas determinações sociais e consciente delas, porém com capacidade (em sua universalidade) de alterar a totalidade social, de criar novas idéias e formas de existência, associando-se a outros em busca da liberdade e da felicidade para todos, a despeito de todo o esforço despendido pela história e pela cultura.

O compromisso social que marca a sua obra é um valor de vida-vivida. Sente-se nela a fé inabalável no potencial transformador do homem e na sua busca irreprimível, apesar das forças alienadoras, do bom, do belo e do verdadeiro:

"Identifico-me com a humanidade como um todo. o que puder fazer em termos de humanidade, estou lá... se tudo o que se faz em função de um bem comum é religioso, eu sou religiosa" (Lane, 1996b).

Ela contribuiu para o questionamento ao slogan, em moda na virada do século, da morte do sujeito e da história, ao defender uma ontologia que não aceita nem o pragmatismo norte-americano, nem a concepção de homem abstrato difundida pela filosofia da linguagem, ou de homem passivo frente à sociedade $\mathrm{O}$ sujeito de suas reflexões é um "sujeito inteiro" ou "inteiramente sujeito", de forma que ser e fazer, razão e emoção, subjetividade e objetividade não se separam. Uma singularidade, mas que não existe em si, só na relação com o outro. Um sujeito histórico, mas que não se reduz a categorias macro-estruturais e não perde a humanidade.

"A gente não pode negar a individualidade, mas também não podemos ignorar que ela tem base na identificação com o próximo e não na distinção do próximo" (Lane, 1998).

Sílvia buscou a transformação social com sofreguidão, pela práxis científica e recusando a violência:

A revolução não tem que ser armada e sim ética $e$ estética... A Psicologia pode e deve contribuir para a reformulação ética e dos valores da nossa sociedade... Talvez seja a minha utopia, mas é por aí. São as pessoas conscientes que serão sujeitos da história. E a nossa função é atuar com os indivíduos para que eles se tornem sujeitos de sua história, e não de uma história individual, mas social também. (Lane, 1998, p. 80).

Essa concepção-compromisso de ciência começou a ser germinada na opção pelo curso de Filosofia da Uni- versidade de São Paulo (USP) motivada pelo desejo precocemente manifesto de compreender o ser humano inteiro, conforme Sílvia nos relata ${ }^{1}$ :

"tinha interesse em neurologia e em arquitetura, quando deparei com um currículo de Filosofia e concluí que ali estava tudo o que me interessava estudar: Psicologia, Ética, Estética, História da Filosofia."

$\mathrm{Na}$ faculdade ${ }^{2}$, aceitou o desafio de colaborar com a realização de uma Psicologia ${ }^{3}$ que não fosse ideológica "Os filósofos quando viam a gente interessar-se por psicologia, diziam: o que você vão fazer nessa ciência ideológica? Eu pensava: ideológica por que? Isso ficou mexendo comigo por muito tempo" (Lane, 2000, p. 5), até se corporificar nos anos 60, época em que o Brasil e a América Latina iniciavam um período político sombrio, marcado pela ditadura militar.

“... o poder repressivo, as injustiças sociais e a opressão sob a qual a maioria dos povos vivia, faziam-nos questionar não só o nosso papel de pesquisadores como a própria psicologia social"(Lane \& Sawaia, 1995a, p. 69).

O ano de 68 foi muito significativo para Sílvia no sentido da consolidação da sua consciência da necessidade de mudança da universidade e da ciência psicológica. Sabe que a crise da Psicologia é também uma crise política:

A Psicologia Social que se apresentava na década de 50 como o ramo da Psicologia que contribuiria para resolver os problemas da humanidade, parecia a nós, neste período que apenas subsidiava a opressão, a manipulação política e a manutenção do status quo. (Lane \& Sawaia, 1995a, p. 69).

A passividade da população era uma indicação de que ela ficava longe dessas questões sociais, de que era um "zero à esquerda", não interferia em nada, não ajudava em nada, quer dizer, era um saber que estava lá, que partia das teorias americanas para explicar a realidade brasileira. "Era preciso compreender como o latino-americano singulariza o universal na constituição particular de sua existência" (Lane, 2000).

Conclui que o caminho para a superação da crise da Psicologia não era o do aprofundamento de uma das teorias dominantes à época, mas o da revolução epistemológica e ontológica, necessária para colocar os pés da ciência psicológica no chão histórico e superar as dicotomias e o conhecimento fragmentado do ser humano pela comportamentalização das teorias. Estas elegiam uma parte do psiquismo para objeto de estudo como se o homem fosse reduzido exclusivamente a ela, à semelhança do homem do inconsciente da psicanálise, do comportamento do behaviorismo e da percepção da gestalt, da linguagem ou ainda a oposição entre 
sociologismo ou psicologismo que marcou a gênese da psicologia social.

Ela gostava de citar um frase de Vygotsky, em texto datado de 1926, em que ele já fazia esse diagnóstico e expunha seu entendimento de como superar essa crise da psicologia, afirmando que a questão primária da psicologia é a questão do método, que é a questão da verdade. E o método capaz de conduzir o conhecimento do real, segundo o autor, é o dialético (Vygotsky, 1927/ 2002a).

Pensando da mesma forma, Sílvia volta-se ao marxismo, escolhido por fazer uma crítica à ideologização da ciência e introduzir a lógica dialética materialista nas ciências humanas, e assim criar um sistema de categorias e conceitos capaz de manter a contraditoriedade do fenômeno psicossocial, sem rupturas entre objetividade e subjetividade, indivíduo e sociedade, mente e corpo. Escolhido, também, por situar "historicamente o 'psiquismo', orientando cada área específica da psicologia a assumir, dentro de sua especificidade, a natureza histórico-social do ser humano" (Lane \& Codo, 1984, p. 19), e, o que é mais importante, sem perder a especificidade da singularidade.

Dessa forma, a Psicologia Social ganharia condições teórico-metodológicas de conhecer o homem e a mulher latino-americanos naquilo que lhes é especifico como naquilo que é manifestação grupal e social e naquilo que é de sua criação, o que significa conhecê-los na dialética subjetividade e objetividade e no diálogo interdisciplinar.

A desconsideração da psicologia pelo ser humano como produto histórico-social é que a torna, se não inócua, uma ciência que reproduziu a ideologia dominante de uma sociedade, levando-a a descrever comportamentos e, baseada em freqüência, tirar conclusões sobre relação causal, reduzindo-se à descrição pura e simples de comportamentos, ocorrendo em situação dadas. (Lane \& Codo, 1984, p. 12).

Ao mesmo tempo, Sílvia sabia que era imensa a responsabilidade dos que optavam por esse referencial, naquele momento histórico, caracterizado por regimes ditatoriais na América Latina e de predomínio do positivismo como paradigma científico das ciências humanas. Pelo fato de questionar o princípio de neutralidade científica e ter sido a ideologia da revolução da URSS, gerava muitas especulações políticas e ideológicas em torno dele.

Esse contexto exigia a legitimidade acadêmica desse referencial crítico por meio de pesquisas rigorosamente científicas, embora sob pressupostos e procedimentos distintos do paradigma dominante, para demonstrar que a negação da neutralidade da ciência e do "mito do método", ao contrário do que se apregoava, garantia a objetividade do conhecimento, superando vícios cindidores.
Começava aí a sua dedicação à pesquisa e ao aprofundamento da metodologia qualitativa

"Eu concordo com Vygotsky que uma nova psicologia só se faz com pesquisa ... A teoria sem a pesquisa é metafísica, a pesquisa sem a teoria é descrição do aparente e ambas, sem a prática, são ingênuas e inócuas" , afirma Lane (1996a, p. 4).

Mais uma vez, fica evidente a coerência entre os pressupostos epistemológicos e ontológicos das reflexões teóricas e os valores de vida-vivida de Sílvia, e entre vida pessoal e acadêmica. A dialética não é um método de pesquisa adotado racionalmente, apenas, mas é uma lógica do pensar, sentir e agir. Ela era dialética por inteiro, conseguia analisar, por sob a aparência, a essência da contraditoriedade dos fenômenos não só na pesquisa mas no dia a dia como afirma Marlito de S. Lima em seu depoimento nesta revista (p.). Tinha aversão ao dogmatismo e reducionismos, ao mesmo tempo que tinha princípios rígidos, em relação aos quais era intolerante. Respeitava e aprendia com as teorias dos grandes pensadores de diferentes correntes, e com seus interlocutores, colegas e alunos, em busca do confronto de idéias sem discriminação ideológica, fiel à lógica dialética que concebe o movimento de transformação da materialidade e da idéias como de superação, um movimento que não rompe ou rejeita o oposto, mas o incorpora em novas formas (a identidade dos fenômenos está na contraditoriedade que os constitui), reorganizando a totalidade do conhecimento sobre o psiquismo.

Essa epistemologia era muito importante para quebrar a lógica que alimentou os dualismos clássicos da Psicologia como a da mente/corpo e da razão/ emoção, e os corporativismo teóricos que separavam o homem do inconsciente, do homem do comportamento, do homem da cognição como se fossem seres diferentes, conforme denunciou Vygotsky, no texto $O$ significado histórico da crise na Psicologia, de 1927/2002a.

Em entrevista à revista Fluxo (Lane, 1998), ela cita uma frase de Gaston Bachelar que representa muito bem essa espistemologia:

a ciência só avança quando o cientista pergunta: "Por que não”. Negar outros conhecimentos é um dogma, e dogmatismo é exatamente o oposto à ciência. $O$ dogma destrói qualquer conhecimento científico. A ciência tem que questionar, entender e debater e não negar simplesmente em nome de uma verdade cristalizada.

Foi assim que construiu sua teoria, sempre como uma síntese inacabada, sensível à história e ao diálogo com outras teorias para evitar o reducionismo e o pensamento único. Superou o behaviorismo e seu a-historicismo conservando o seu pressuposto da materialidade do fenômeno psicológico e o respeito ao dado empírico, a 
representação social e o cognitivismo, mantendo a idéia de significado e sentido e a importância da linguagem e da cultura.

Vamos destacar, nesse processo, quatro momentos de síntese da mais radical superação na teoria laneana que foi a transição de um referencial teórico-metodológico centrado na contribuição de Lewin, Mead, Skinner ao marxismo: (a) dos anos 70, marcado pelo diálogo privilegiado com a teoria das representações e pela preocupação com a linguagem e grupos sociais; (b) dos anos 80 , momento das vigorosas reflexões sobre uma nova concepção. de homem para a Psicologia, com ênfase nas categorias de consciência e alienação; (c) dos anos 90, caracterizado pela reflexão sobre o papel da subjetividade/afetividade na conscientização social e na ação transformadora; (d) a do novo milênio, dedicado a desvelar os segredos da criatividade humana.

Três temas são constantes em todos esses momentos: ideologia, linguagem e grupos sociais. São os temas de sua vida. O interesse de Sílvia pela linguagem e a sua constatação de sua importância social e individual vem da infância.

Sílvia cresceu no seio de uma família que só falava o alemão em casa, até o dia em que, quando tinha sete anos, sabendo das hostilidades sofridas pelos alemães no Brasil no final da segunda guerra, propôs aos pais que falassem português, pelo menos na presença de pessoas estranhas, insistindo na necessidade de sua mãe aprender a língua da terra, no que foi atendida, para evitar discriminação e preconceito.

Também, o clima intelectual de sua casa a influenciou, um clima de discussões abertas sobre religião (hermenêutica) e filologia, entre seu pai, um estudioso, avesso às ortodoxias e seu tio Henrique, que foi professor de Filologia Românica, na Universidade de São Paulo (USP) e também pastor presbiteriano que fundou uma seita dissidente por não concordar com interpretações presbiterianas da bíblia como crença na existência do diabo; pois "se Deus criador do universo é amor, como, com sua onipotência, poderia admitir a criação do Mal?"

Mais tarde, esse interesse é reforçado pelos professores da faculdade de filosofia, como já dito acima, que lhe lançaram o desafio de realizar uma psicologia que não fosse ideológica. Para tanto, intui a necessidade de aprofundar os conhecimentos sobre a linguagem e o significado dela no conjunto das relações humanas, afetivas, sociais (objeto de sua tese de doutorado).

O interesse pelo grupo como objeto da ação e da pesquisa da psicologia social foi despertado na faculdade, resultado da obra de Lewin, da influência de sua professora de psicologia, Anita Cabral, e foi reforçado pelas reflexões de Martin-Baró e pela proposta de ação co- munitária que começava a surgir no bojo da psicologia comunitária latino-americana.

A esses temas se agregaram três outros: consciência, emoção e criatividade, que transformaram o referencial anterior como um todo, configurando uma rede de categorias analíticas com competência para mediar a construção de conhecimentos psicossociais situados na particularidade histórica da América-Latina, mas ao mesmo tempo universal, voltado à transformação social pela ação coletiva, mas focado nas singularidades.

Vejamos uma síntese de cada um dos quatro períodos:

1. A produção dos anos 70 é marcada pela preocupação com a linguagem e grupos sociais, bem como pelo diálogo entre seus autores de referência $\left(\right.$ Lewin, Skinner, Mead e Osgood ${ }^{4}$ ) com as pesquisas interculturais de Aniela Ginsberg e, mais tarde, com a teoria das representações sociais de Moscovici e Jodelet.

"as pesquisas de Dra. Aniela apontavam para a relatividade do comportamento humano em função de diferenças históricas, culturais e sociais, tudo indicando que não cabia à psicologia, como ciência, ter leis universais" (Lane \& Sawaia, 1995b, p. 67).

Junto com essa grande pesquisadora (que legou sua herança para criar um Fundação de Apoio à Pesquisa na Faculdade de Psicologia da Pontifícia Universidade Católica de São Paulo - PUC-SP), Sílvia batalhou pela criação do Programa de Estudos Pós-graduados em Psicologia Social da PUC-SP, universidade que, no período, centralizava a resistência acadêmica ao regime militar.

O objetivo mais amplo era a criação de uma psicologia social latino-americana.

Como não podia deixar de ser, o Programa nasce interdisciplinar e centrado na realidade brasileira. Ela própria elabora a ementa de uma disciplina básica do curso, denominada de Psicologia Social e realidade brasileira, cujo objetivo era de levar o aluno a conhecer alternativa de estudos críticos em psicóloga social, refletir sobre os compromissos do psicólogo social em desenvolver trabalhos científicos que fossem fator de transformação, para tanto era preciso eliminar a separação entre psicologia e as ciências sócias.

Duas influências marcantes nesse período vêm da França: a teoria das representações e a constatação do perigo do dogmatismo na adoção, por parte da psicologia, do marxismo. Sílvia buscou uma interlocução com psicólogos sociais desse país para conhecer os frutos teórico-metodológicos da crítica que faziam à psicologia social americana e à psicanálise, especialmente as realizadas pelo Laboratório de Psicologia Social de Paris VII e pela Escola de Altos Estudos em Ciências Sociais da Sorbonne (EHESS). 
É convidada por Denise Jodelet ${ }^{5}$ e Moscovici a passar o mês de janeiro de 86 como diretora de estudos associados, na referida escola e para participar do Encontro sobre "Pensamento Científico/Pensamento Natural", promovido por essa mesma instituição. Nessa ocasião teve a oportunidade de discutir a produção brasileira de psicologia social, com esses dois importantes teóricos da psicologia social, criadores da teoria da Representação Social:

"Eles ficaram muito interessados, considerando que nós havíamos rompido com o academicismo ainda arraigado na Europa e reforçaram a minha convicção de que esse é o caminho para uma Psicologia Social atuante" (Lane, 2000).

Também debateu com os pesquisadores do Laboratório Europeu de Psicologia Social, onde conheceu o pesquisador alemão Klauss Scherer que a convidou, mais tarde, a participar de uma pesquisa intercultural sobre o caráter sócio-cultural das emoções. Ainda conversou com Robert Pagès, diretor do Laboratório de Paris VII, para obter subsídios à implantação de um laboratório de pesquisa no Programa de Pós-Graduação em Psicologia Social da PUC-SP.

Junto com o entusiasmo do estímulo recebido e com as novas produções teóricas que conheceu, volta preocupada com o reducionismo e o determinismo que a teoria marxista estava sofrendo em algumas reflexões. Segundo Lane, nos anos 70, o Laboratório de Psicologia Social de Paris VII, (Pecheux, Pagés, Poitou) começa a produzir analises críticas e pesquisas sob uma ótica marxista. No entanto, esses autores, comprometidos com uma atuação partidária no Partido Comunista, promoveram um dogmatismo teórico, que, apesar das grandes e profundas reflexões teóricas, deixou a prática e a pesquisa quase inalteradas.

A preocupação em evitar esse perigo de sobrepor a teoria à realidade a fez interessar-se pela teoria das representações que, segundo ela, delineia o objeto empírico da psicologia social, sintetizando em um único conceito a linguagem, o pensamento, a comunicação e a cultura:

\section{A Representação Social, ou seja, a verbalização das concepções que o indivíduo tem do mundo que o cerca ... caracteriza-se como um comportamento observável e registrável e como um produto, simulta- neamente, individual e social, estabelecendo um forte elo conceitual entre a psicologia social e a sociologia. (Lane, 1993, p. 59).}

Neste mesmo texto ela apresenta o caminho percorrido por esse conceito em sua teoria, e de como ele contribuiu para o avanço de sua teoria dialética materialista, "pois ela constitui o dado empírico do qual se parte para uma análise dialética, que permite conhecer concretamente a consciência, a atividade e a identida- de de sujeitos situados social e historicamente" (Lane, 1993, p. 68).

Por outro lado, é preciso salientar que essa é a época também do crescimento do movimento da anti-psiquiatria e da educação popular, o primeiro como movimento de desospitalização e crítica aos manicômios e à elitização da psicologia, propondo a sua inserção nas comunidades populares. O segundo como instrumento de conscientização social e respeito ao saber popular, liderado por Paulo Freire. Esses dois movimentos de reação à crise das ciências humanas levam psicólogos a desenvolver atividade em comunidades pobres, tendo como meta a conscientização popular das injustiças e desigualdades, visando ações transformadoras. "Nesta década, começa a se expandir, sob o título de Psicologia Social Comunitária, uma prática centrada na prevenção da saúde mental e em uma educação popular, na qual participam pedagogos, psicólogos, sociólogos e trabalhadores sociais" (Lane \& Sawaia, 1995a, p. 70).

Nesse contexto, a grande dama da psicologia social brasileira $^{6}$ faz uma revisão crítica das teorias e técnicas de dinâmica de grupo, principalmente do conceito de líder e de coesão social, destacando o caráter ideológico, a-histórico e reificado dessas teorias. Substitui o conceito de grupo por processo grupal para enfatizar o seu movimento histórico e o insere no bojo das reflexões sobre comunidade e atividades de conscientização, propondo-se a "estudar o processo grupal em bases materialistas-históricas e dialeticamente" (Lane \& Sawaia, 1995a, p. 70).

Com Abib Andery ${ }^{7}$, muda a estratégias de estágio na graduação, criando um campo de ação psicossocial dos estudante da faculdade de psicologia da PUC-SP, que foi o germe da Psicologia Comunitária em São Paulo.

Preparavam-se, assim, as bases para a segunda fase, como indica em seu texto Uma Redefinição da psicologia Social, de 1980.

2. A década de 80 foi o momento mais vigoroso de suas reflexões e pesquisas, em que delineia uma nova concepção de homem para a psicologia, com ênfase nas categorias de consciência e alienação.

Momento em que a sua teoria em construção torna-se conhecida e atrai interessados do Brasil todo, muitos procurando-a para orientar suas dissertações e teses. Essa produção é muito bem retratada no livro Psicologia Social: O homem em movimento, em 1984, que em 2000 estava na $14^{a}$ edição.

É forte a influência do marxismo, especialmente por meio das obras da escola de psicologia soviética (Vygotsky, Luria e Leontiev) e dos neo-marxistas. É significativa a contribuição da obra de George Politzer para a reflexão sobre a elaboração de uma psicologia concre- 
ta; de Lucien Séve para a discussão filosófica do conceito de personalidade em bases marxista; de Lefébvre para discutir a lógica dialética e de um epistemólogo da psicologia social, Frederic Munné, com o livro intitulado "Psicologias Marginais", em que apresenta grandes pensadores e teóricos esquecidos pela psicologia oficial, dentre eles, a escola soviética de Vygotsky, a obra de Rubeinstein e a escola de budapeste de Agnes Heller. Esta última, Heller, com suas reflexões sobre a relação entre cotidiano e história, sobre a teoria das necessidades em Marx, e sobre emoção/afeto/sentimento, ressaltando o poder da vergonha na configuração da consciência.

O encontro com dois psicólogos latino-americanos, nos anos 80, que fizeram o doutoramenteo na Rússia, orientados por discípulos da escola soviética vygotskiana, Mário Golder, da Universidade de Buenos Aires e Fernado Gonzalez Rey, da Universidade de Havana, foram fundamentais para o direcionamento teórico no sentido de escapar do reducionismo mecanicista e estruturalista, que levava muitas análises psicossociais, inspiradas no marxismo, a perder o sujeito em categorias macro-estruturais ou reduzi-lo a mero reflexo (caixa de ressonância) da materialidade sócio-ecônomica.

Rey e Golder colaboraram com a descoberta de textos inéditos do grupo de Vygotsky e com a superação tanto da leitura interacionista quanto reflexológica que a obra dele recebia nos EUA e no Brasil, apresentando a riqueza de análise dialética do processo de constituição do psiquismo na materialidade histórica de cada sociedade, o que não implica a perda da criatividade humana.

A trinca de pesquisadores soviéticos (psicologia) sofreu, na década de 30 e 40, a repressão stalinista que proibiu a divulgação de sua obra na Rússia. Após a queda de Stalin, ela continuou restrita às fronteiras da União Soviética, até a queda do muro de Berlim. Suas únicas obras conhecidas no ocidente, até então, eram os trabalhos de psiconeurologia de Luria e as reflexões sobre desenvolvimento infantil e educação de Vygotsky.

Sílvia encontra nesses psicólogos soviéticos os interlocutores privilegiados pela incrível coincidência de interesses e de opções teórico-metodológicas. No inicio do século, eles revolucionaram a psicologia soviética, motivados por uma extrema insatisfação com as teorias clássicas da psicologia que promoviam a dicotomia entre mente e corpo, homem e sociedade e pela constatação de que a superação do que eles denominavam de "crise da Psicologia" estava no método dialético. Igualmente à Sílvia, eles consideravam a linguagem um conceito básico da psicologia, pelo seu papel de mediação social, e buscaram a lingüística para aprimorar esse conceito.

Se esse é o período de maior produtividade e visibilidade de sua produção, também é o período em que Síl- via é bombardeada por críticas dos grupos que definiam o paradigma da psicologia social brasileira, cuja liderança era exercida por Aroldo Rodrigues.

Daí, a urgência em ganhar legitimidade científica e acadêmica.

Buscou parceiros na América Latina, realizando uma viagem por este continente ${ }^{8}$, em que aprendeu muito e serviu para mostrar o quanto Sílvia já havia avançado em seus estudos e que estava no caminho certo para fortalecer o paradigma latino americano em formação, tendo como principal teórico o jesuíta salvadorenho Martín-Baró que se tornará, a partir de então, o seu mestre ${ }^{9}$. Especialmente por sua preocupação em "deslindar as determinações da alienação, ou seja a falta de controle da maiorias populares sobre sua própria existência e destino" (Lane \& Sawaia, 1995a, p. 72). Também, por demonstrar o processo de desenvolvimento de uma consciência social e a do grupo nesse processo. "Sua obra é tão completa neste sentido que o curso de Processo Grupal que ministramos no Programa de Pós-Graduação tem no seu livro: Sistema, grupo e poder uma leitura básica e obrigatória" (1995a, p. 71).

Nessa viagem também conheceu atividades que a Psicologia comunitária desenvolvia a partir do referencial da pesquisa participante, como as experiência de Elisa Jimenez, Ester Wiesenfeld e Maritza Montero, em Caracas, e de Fals Borda, criador dessa metodologia na Colômbia. Referenciais importantes que lhe permitiram "reformular a práxis da Psicologia Social e a nossa metodologia de pesquisa" (Lane \& Codo, 1984, p. 71), para garantir a indissociabilidade entre teoria e pratica.

"Pudemos constatar que, quando pessoas se unem em grupos e resolvem ser sujeitos de sua histeria e encontram assessoria qualificada, conseguem avançar em direção a relações sociais essencialmente democráticas, nos seus direitos e deveres, que caracterizam uma comunidade" (Lane \& Sawaia, 1995a, p. 72).

Paralelo ao entusiasmo com a possibilidades da Psicologia Comunitária crítica de oferecer bases para uma atuação transformadora, voltou com a certeza da necessidade de uma sistematização e aprofundamento das reflexões teóricas sobre as bases psicossociais da ação comunitária. Considerava que o desenvolvimento dessa área de conhecimento e ação estava sendo feita por erros e acertos sem avanços mais significativos, dominada pelo ativismo, com a conseqüente ausência de publicações teóricas, sendo que os raros textos em circulação restringiam-se à descrições das ações.

Para ela a questão da indissociabilidade entre teoria e prática sempre foi um problema não resolvido pela Psicologia Social, que não conseguia que a sistematização teórica produzisse efeitos práticos e a prática redundasse em novas reflexões teóricas. 
Foi este o desafio que caracterizou a Psicologia Social da década de 80, pois mediante uma prática do psicólogo em comunidades se procurou uma sistematização teórica, e, por meio de pesquisas . . buscou-se encontrar formas de atuação para que, em ambos os casos, houvesse transformação significativas para as populações desfavorecidas da América latina. (Lane \& Sawaia, 1995a, p. 71).

3. Nos anos 90 , vai aprofundar esta sistematização teórica, especialmente sobre o papel da subjetividade/afetividade na conscientização social e na ação comunitária transformadora, para superar as concepções e práticas psicossociais que aprisionavam o sujeito à exterioridade e à pura repetição, expurgando a singularidade tanto da teórica quanto da ação. Para tanto, reafirma a opção pela metodologia da pesquisa participante que demarca a diferença entre práxis científica rigorosa com compromisso social e militância e o diálogo natural entre prática e teoria no processo da pesquisa.

A grande motivação e a base dos dados para essas análises foram as teses e dissertações de seus orientandos. Esta sistematização está registrada no livro Novas veredas da psicologia Social (Lane \& Sawaia, 1995b) e no texto Psicologia Comunitária: Histórico e fundamentos da Psicologia Comunitária no Brasil de 1996 (Lane, 1996b). Textos importantes para exemplificar o processo de superação dialética que caracteriza o desenvolvimento de sua teoria. Por meio deles acompanha-se cada um dos momentos de mudança dos seus principais conceitos: grupo, linguagem e consciência, em que eles incorporam a dialética subjetividade e objetividade e singularidade/história.

O grupo continuou sendo o campo de ação privilegiado da psicologia social e a representação social (linguagem) o seu objeto, entendendo que ambos são vínculos essenciais entre o individuo e a sociedade. Também a consciência, mais especificamente a conscientização para superar a ideologia e a alienação, continua o objetivo central da práxis psicossocial. No entanto, esses conceitos foram transformados, passando a incorporar as emoções, os afetos e os sentimentos em suas bases, entendendo que elas dão sustentação tanto às desigualdades, relações de poder e alienação quanto às resistências a essas determinações sociais.

Nesse contexto analítico, a reflexões de Vygotsky, especialmente sobre sentido e significado, contribuíram para a superação da dicotomia entre singularidade e história. Segundo ele, a linguagem tem duas dimensões, uma relacionada à subjetividade individual e a outra às idéias socialmente circulantes e dominantes, portanto, ambas na sua identidade dialética constituem a unidade analítica do comportamento humano capaz de incluir todas as manifestações psicossociais e definir que a subjetividade é sempre intersubjetividade

Esse referencial lhe permitiu trabalhar duas dimensões aparentemente antagônicas da linguagem: o seu caráter de mediação no processo de constituição da subjetividade, transposição do social ao subjetivo, e também o lado criativo e ativo do homem no uso da linguagem $^{10}$.

4. Ś́lvia entra no novo milênio com a preocupação de desvelar os segredos da criatividade humana. Emoção, arte e criação são os temas que passaram a mediar a sua incessante reflexão crítica das teorias psicossociais, tanto que incorpora no rol de seus interlocutores artista plásticos e músicos compositores.

O livro representativo desse momento de sua teoria é o Arqueologia das emoções publicado em 2000 (Lane \& Araújo, 2000).

É importante ressaltar que o interesse pela criatividade está atrelado à sua inabalável luta em defesa da liberdade. Para atingir a autonomia é necessário desenvolver a criatividade e a imaginação, refletia ela, sendo que toda força criadora encerra elementos afetivos. E, bem humorada, nos provocava afirmando que, ao contrário dos psicólogos e cientistas sociais, a ideologia e a alienação sabiam disto muito bem, haja vista os bloqueios impostos a essas funções psicológicas, inclusive nas escolas e nas famílias.

Novamente, encontra em Vygotsky um interlocutor. A relação entre significado, imaginação, criação e liberdade é a equação básica da obra desse pesquisador soviético. A atividade de significar é uma expressão da atividade revolucionaria, pois permite ao homem libertar-se das leis da natureza e das determinações sociais, que o destinam à mera repetição. Ele apontava a arte como expressão dessa energia criativa que impulsiona a mudança pela criação do novo.

“. . . As possibilidades de agir com liberdade, que surgem na consciência do homem, estão estreitamente ligadas à imaginação, ou seja, a tão peculiar disposição da consciência acerca da realidade, que surge graças à atividade da imaginação" (Vygotsky, 2002b, p. 438).

A ênfase na criatividade fecha o circulo dialético de configuração da ontologia laneana. Ao inserir na reflexão sobre subjetividade, a estética, a imaginação e os afetos, ela está reconhecendo aos homens o seu direito de ter necessidades elevadas, como a do belo, e que este é um desejo de todos e não só dos que superaram a luta pela sobrevivência, tão fundamental quanto o alimento para se manter vivo como ser humano.

A necessidade do belo e a energia criativa, possibilitada pela capacidade de signalizar e imaginar, torna o 
homem capaz de romper a causação circular entre determinação social, alienação e individualismo. Por isso que toda política sócio-econômica excludente precisa, para se reproduzir, inibir a imaginação, a sensibilidade estética e bloquear os afetos, instalando uma política de cristalização da capacidade de afetar e ser afetado.

Fecha também o circulo dialético de sua práxis, deixando claro que, ao se pensar em revolução, é preciso pensar em novas formas de (inter)subjetividades e para tanto em novas formas de atividade. Pois é nela que as subjetividades são modeladas e plasmadas. Mas, para que haja novas formas de atividade é preciso pensar em criação e imaginação.

Após essa breve síntese da teoria laneana, uma pergunta irrompe naturalmente: E, agora, que fazer com este importante legado?

Sílvia, certamente, ficaria muito decepcionada se os conhecimentos que nos ofereceu fossem apenas repetidos, reproduzidos sem o olhar crítico e a atitude criativa que ela sempre priorizou como condições indispensáveis na produção de conhecimento.

Ela antecipou aquilo que era necessário para a psicologia social livrar-se do caráter ideológico, denunciado por seus professores do curso de filosofia. Superou a separação artificial entre as ciências humanas e os dualismos retalhadores do homem. Ensinou-nos que o respeito ao fato empírico e ao rigor científico não é antagônico ao compromisso social, e que, para a psicologia social brasileira o norte é a produção de conhecimento com capacidade de intervir na condição social da América-Latina.

Enfim, criou uma metodologia "prático-crítica-revolucionária", ao mesmo tempo em que nos ofereceu, muito, muito afeto, encantamento e alegria de vida.

A ela, que foi a demonstração viva do sujeito espinosano: um grau de potência ao qual corresponde um poder de ser afetado e afetar, uma forca de expansão e liberdade irreprimíveis que a sociedade não conseguiu destruir, nem mesmo a morte, o nosso tributo não pode ser outro que continuar, com entusiasmo, a processualidade de sua "concepção-compromisso" de ciência em busca do conhecimento da existência humana feliz, porque ética como ela. O que não nos impede de exclamar:

Mas que saudades!

\section{Notas}

1. O envolvimento entre vida pessoal e profissional, aspectos subjetivos e opções teóricas e a sua produção cientifica é claramente demonstrada na entrevista elaborada por Maria. Helena Coelho, nesta revista (p. 7).

2. Optou, durante o curso de filosofia pela psicologia, e passou a exercê-la na docência e na pesquisa. E quando o Ministério de Educação (MEC) iniciou um processo de avaliação dos primeiros registros de psicologia, teve a solicitação de reconhecimento de seu título de psicóloga recusado. Conforme afirmava Sílvia, "na época, só conseguia o registro quem aplicava o RAVEN e fazia terapia. Para eles, pesquisador não era psicólogo. Isso valeu para me definir como professora de psicologia e ponto e assumir que não queria exercer a profissão de psicólogo, tida exclusivamente como clínica e aplicação de testes." (Lane, 2000, p. 5).

3. Na época, a faculdade de filosofia da USP oferecia a habilitação em psicologia.

4. Ver sua tese de doutorado: Os significados psicológicos das palavras em diferentes grupos, de 1972, na PUC-SP e texto publicado na Revista Psicologia em co-autoria com Sawaia Elcie.

5. Ver depoimento de Denise Jodelet nesta revista (p. 37).

6. Expressão usada por Jodelet, em seu depoimento, nesta publicação (p. 37).

7. Ver depoimento de Abib Andery, nesta publicação (p. 28).

8. Ver texto de Maria do Carmo Guedes, sua companheira nessa viagem, (p. 39) nesta publicação.

9. Sílvia sofreu muito com o assassinato de Baró, em 1989, tendo desencadeado, no Brasil um movimento de denúncia ao caráter político de sua morte.

10. Essa passagem teórica sofreu resistências dentro do núcleo da Sílvia. Presenciei calorosos debates entre os membros que não aceitavam introduzir na psicologia social sócio-histórica o significado como categoria de mediação entre o homem e sociedade, por acreditar que assim se perdia a materialidade e se caía no idealismo. O outro grupo considerava que o risco era infundado pois a categoria de significado/sentido de Vygotsky introduzia a contraditoriedade coletivo/singular, história/cotidiano e instrumento/ pensamento na categoria de consciência e demarcava o processo de conscientização como potência da ação transformadora. Sílvia conduzia sem pressa os debates, de forma a aprofundar as reflexões, até que não pairassem dúvidas sobre a necessidade da dimensão do significado para garantir a univocidade dialética da teoria materialista histórica.

\section{Referências}

Lane, S. (1980, jun.). Uma redefinição da Psicologia Social. Educação \& Sociedade, 2(6), 96-106.

Lane, S. (1993). Usos e abusos do conceito de representações sociais. In M. J. Spink (Ed.), O conhecimento no cotidiano: As representações sociais na perspectiva da Psicologia Social (pp. 58-72). São Paulo, SP: Brasiliense.

Lane, S. (1996a). Histórico e fundamentos da Psicologia Comunitária no Brasil. In R. H. F. Campos (Ed.), Psicologia Social Comunitária: Da solidariedade à autonomia (pp. 17-34). Petrópolis, RJ: Vozes.

Lane, S. (1996b). Para pensar... e depois fazer [Entrevista]. Psicologia \& Sociedade, 8(1), 3-15.

Lane, S. (1998). Entrevista. Fluxo: Revista dos alunos de Ciências Humanas da PUC-SP, 2(2), 75-82.

Lane, S. T. M. (2000, maio/jun.). Diálogos: Uma psicologia para transformar a sociedade [Entrevista]. PSI Jornal de Psicologia, São Paulo, 18(122), 4-6. 
Lane, S., \& Araújo, Y. (Eds.). (2000). Arqueologia das emoções. Petrópolis, RJ: Vozes.

Lane, S., \& Codo, W. (Eds.). (1984). Psicologia Social: O homem em movimento. São Paulo, SP: Brasiliense.

Lane, S., \& Sawaia, B. (1995a). La Psicología Social Comunitaria en Brasil. In E. Wiesenfeld \& E. Sánchez (Eds.), Psicología Social Comunitária: contribuições latinoamericanas (pp. 69116). Caracas, Venezuela: Tropykos.

Lane, S., \& Sawaia, B. B. (Eds.). (1995b). Novas veredas da Psicologia Social. São Paulo, SP: Brasiliense.

Vygotsky, L. S. (2002a). O significado histórico da crise na Psicologia. In Obras Escogidas: Vol. 1. Madrid, España: Visor. (Original publicado em 1927)

Vygotsky, L. S. (2002b). Obras Escogidas: Vol. 2. Madrid, España: Visor.

Bader Burihan Sawaia é graduada em Ciências Sociais, mestre e doutora em Psicologia Social. Professora titular da Pontifícia Universidade Católica de São Paulo (PUC-

SP) na Pós-graduação de Psicologia Social. Endereço para correspondência: PUC-SP, Rua Monte Alegre, 984,

Perdizes, São Paulo, SP, 05014-001.

badbusaw@pucsp.br

Teoria Laneana: a Univocidade radical aliada à dialética-materialista na criação da Psicologia Social histórico-humana

Bader Burihan Sawaia

Recebido: 01/08/2007

Aceite Final: 14/09/2007 